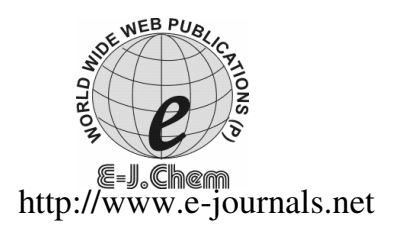

ISSN: 0973-4945; CODEN ECJHAO

E-Journal of Chemistry

2011, 8(3), 1014-1021

\title{
A Comparative Study of Carbon Nanotubes Synthesized from Co/Zn/Al and Fe/Ni/Al Catalyst
}

\author{
EZEKIEL DIXON DIKIO \\ Department of Chemistry, Vaal University of Technology \\ P. O. Box X021, Vanderbijlpark 1900, South Africa \\ ezekield@vut.ac.za
}

Received 11 August 2010; Accepted 8 November 2010

\begin{abstract}
The catalyst systems $\mathrm{Fe} / \mathrm{Ni} / \mathrm{Al}$ and $\mathrm{Co} / \mathrm{Zn} / \mathrm{Al}$ were synthesized and used in the synthesis of carbon nanotubes. The carbon nanotubes produced were characterized by Field Emission Scanning Electron Microscope (FESEM), Energy Dispersive x-ray Spectroscopy (EDS), Raman spectroscopy, Thermogravimetric Analysis (TGA) and Transmission Electron Microscope (TEM). A comparison of the morphological profile of the carbon nanotubes produced from these catalysts indicates the catalyst system $\mathrm{Fe} / \mathrm{Ni} / \mathrm{Al}$ to have produced higher quality carbon nanotubes than the catalyst system $\mathrm{Co} / \mathrm{Zn} / \mathrm{Al}$.
\end{abstract}

Keywords: Carbon nanotubes, Synthesis, Catalyst, Raman, TGA, EDS.

\section{Introduction}

Carbon nanotubes (CNT) long, thin carbon wire just a nanometer or so across, but up to many thousands of times longer-possess exciting mechanical, optical and electrical properties that would make them ideal nanoscale materials. As other useful properties are discovered, particularly strength, interest has grown in potential applications. They could be used, for example, in nanometer-sized electronics or to strengthen polymer materials for use in air and spacecrafts ${ }^{1-6}$. Carbon nanotubes can be produced by arc discharge, laser-ablation or by plasmaenhanced chemical vapor deposition (PECVD) as well as by thermal chemical vapor deposition.

A technique for the synthesis of carbon nanotubes by catalytic decomposition of hydrocarbons was recently reported in which hydrocarbons are decomposed directly into hydrogen and carbon. Catalytic chemical vapor deposition (CCVD), arc discharge and laser ablation remain the three major synthesis routes for CNT production ${ }^{7-11}$. The catalytic chemical vapor deposition (CCVD) technique can be performed in the absence of a substrate that is homogeneous with the catalyst is in the gas phase ${ }^{12}$.

The role of the catalyst is crucial to get high activity and special selectivity towards CNT formation. Cobalt and other ferrous metals and their alloys are the active metals usually employed in the constitution of the catalyst ${ }^{4,13-16}$. 
During this study, iron-nickel catalyst on aluminium oxide, support, $\mathrm{Fe} / \mathrm{Ni} / \mathrm{Al}$ and cobalt-zinc with aluminium oxide, $\mathrm{Co} / \mathrm{Zn} / \mathrm{Al}$, were prepared $^{3,17}$ as catalysts for the synthesis of multiwall carbon nanotubes (MWCNT) with ethyne (acetylene) as carbon source. The use of iron and nickel with a combination of other metals as catalysts in the presence of acetylene for the synthesis of MWCNT has been reported by several researchers ${ }^{18-21}$. In this work, we have synthesized carbon nanotubes from two catalyst systems and then compared the quality of carbon nanotubes produced from these catalyst systems. A comparison of this nature is necessary to establish which catalyst system produced higher quality carbon nanotubes.

\section{Experimental}

The catalyst samples were prepared by co-precipitation method described by Benito et $a l^{4}$ and $\mathrm{Liu}^{18}$. This was achieved by mixing aqueous solution of chlorides of the metals cobalt, zinc and aluminium in the desired amounts, with an aqueous solution of sodium carbonate and sodium hydroxide at room temperature. The $\mathrm{pH}$ of the synthesis was kept at a constant value of $\mathrm{pH} 9$ by drop wise addition of a $1 \mathrm{M}$ sodium hydroxide solution from a burette. The molar ratios used were $\mathrm{Co}^{2+} / \mathrm{Zn}^{2+} / \mathrm{Al}^{3+}=1: 1: 2$. The slurry obtained was dried in the oven for different periods of time $(10,30,60180$ and $300 \mathrm{~min})$ at $125^{\circ} \mathrm{C}$. The precipitates were then washed and dried at $40{ }^{\circ} \mathrm{C}$ in an open air oven. The catalyst samples were calcined at $600{ }^{\circ} \mathrm{C}$ in air. The final temperature was maintained for two hours.

\section{Preparation of catalyst ( $\mathrm{Fe} / \mathrm{Ni} / \mathrm{Al}$ )}

The catalyst was prepared by co-precipitation method ${ }^{4,22}$. A $0.25 \mathrm{M}$ aqueous solutions of $\mathrm{Fe}\left(\mathrm{NO}_{3}\right)_{3} \cdot 9 \mathrm{H}_{2} \mathrm{O}$ and $\mathrm{Ni}\left(\mathrm{NO}_{3}\right)_{2} \cdot 6 \mathrm{H}_{2} \mathrm{O}$ were prepared and mixed in a 1:1 ratio with $\mathrm{Al}_{2} \mathrm{O}_{3}$ powder. The $\mathrm{pH}$ of the synthesis was kept at a constant value of $\mathrm{pH} 9$ by drop wise addition of a $1 \mathrm{M}$ sodium hydroxide solution from a burette. The molar ratios used were $\mathrm{Fe}^{3+} / \mathrm{Ni}^{2+}=1: 1$. The slurry obtained was dried in the oven for different periods of time $(10,30,60180$ and $300 \mathrm{~min})$ at $125{ }^{\circ} \mathrm{C}$. The precipitates were then washed and dried at $40{ }^{\circ} \mathrm{C}$ in an open air oven. The catalyst samples were calcined at $600{ }^{\circ} \mathrm{C}$ in air. The final temperature was maintained for two hours.

\section{Preparation of carbon nanotubes}

Experimental procedure employed in the synthesis has been reported elsewhere ${ }^{23}$. The reactor consisted of a $40 \mathrm{~mm}$ o.d $\times 70 \mathrm{~cm}$ long quartz tube heated by an electrical tube furnace with a temperature controller. Nitrogen gas flowing at $40 \mathrm{~mL} \mathrm{~min}{ }^{-1}$ was passed through the reactor for approximately $70 \mathrm{~min}$., after stabilization for $10 \mathrm{~min}$, the nitrogen gas flow was maintained at $240 \mathrm{~mL} \mathrm{~min}$. The ethyne gas with a flow rate of $90 \mathrm{~mL} \mathrm{~min}^{-1}$ was then passed through the reactor for $60 \mathrm{~min}$. The catalyst (cobalt-zinc-aluminium) and then (iron-nickel-aluminium) were placed on a quartz boat in the centre of the furnace one after the other during the synthesis. The flow rate of the gases was controlled by a mass flow controller (MFC). After the reaction had taken place, the reactor was cooled to room temperature with nitrogen flowing at $40 \mathrm{~mL} \mathrm{~min}^{-1}$ for 3 to $4 \mathrm{~h}$. The samples obtained by this method were then characterized as described below.

\section{Characterization}

The morphological features of MWCNT were analyzed by Raman spectroscopy, FE-SEM, HR-TEM, EDS and TGA. The Raman spectra were obtained by a Raman spectroscope, Jobin-Yvon HR800 UV-VIS-NIR Raman spectrometer equipped with an Olympus BX 40 
attachment. The excitation wavelength was $514.5 \mathrm{~nm}$ with an energy setting of $1.2 \mathrm{mV}$ from a coherent Innova model 308 argon-ion laser. The Raman spectra were collected by means of back scattering geometry with an acquisition time of 50 seconds. The surface morphology and EDS measurements were recorded with a JEOL $7500 \mathrm{~F}$ field emission scanning electron microscope. The HR-TEM images of the sample were obtained by a CM 200 electron microscope operated at $100 \mathrm{kV}$. The thermal behavior of the carbon nanotubes and the catalyst were investigated by TGA using a Q500 TGA instrument under an air environment. The prepared MWCNT samples were heated in platinum crucibles with oxygen and nitrogen gases at a flow rate of 40 and $60 \mathrm{~mL} / \mathrm{min}$ respectively. The dynamic measurement was made between ambient and $1000{ }^{\circ} \mathrm{C}$ with a ramp rate of $10{ }^{\circ} \mathrm{C} / \mathrm{min}$ to $900{ }^{\circ} \mathrm{C}$.

\section{Results and Discussion}

The Raman spectra of the prepared CNTs are presented in Figure 1. Raman spectroscopy is a powerful tool for the characterization of CNTs and can reveal several properties of CNTs. The Raman spectra of the samples, Figure 1, show two major peaks: the $D$ and $G$ bands which indicate the presence of crystalline graphitic carbon in the CNTs. The $D$ bands at $1340 \mathrm{~cm}^{-1}$ and $1350 \mathrm{~cm}^{-1}$ have been attributed to the presence of amorphous carbon ${ }^{18,19}$ due to surface defects of carbon nanotubes. The $G$ bands at $1580 \mathrm{~cm}^{-1}$ and $1584 \mathrm{~cm}^{-1}$ are due to the presence of ordered carbon nanotubes in the prepared samples. The $D$ and $G$ bands in the Raman spectra produce an overtone which resonates at about $2600 \mathrm{~cm}^{-1}$. The presence of this resonance peak in a CNTs synthesis could be related to the amount of carbon nanotubes produced in the synthesis as well as their purity. The absence of this resonance peak in the carbon nanotubes synthesized from the catalyst system $\mathrm{Co} / \mathrm{Zn} / \mathrm{Al}$, Figure 1(a) and its presence in the carbon nanotubes synthesized from the catalyst system Fe/Ni/Al, Figure 1(b) is an indication that the catalyst system $\mathrm{Fe} / \mathrm{Ni} / \mathrm{Al}$, produced a better and purer yield of carbon nanotubes compared to the catalyst system $\mathrm{Co} / \mathrm{Zn} / \mathrm{Al}$. The intensity ratio of these two bands $\left(I_{D} / I_{G}\right)$ is also considered as a parameter to characterize the quality of CNTs samples, with a higher intensity ratio indicating a higher degree of disorder in the CNTs. The intensity ratio for the two peaks obtained is moderate, showing that a good percentage of CNTs were formed in the synthesis using both catalysts systems.

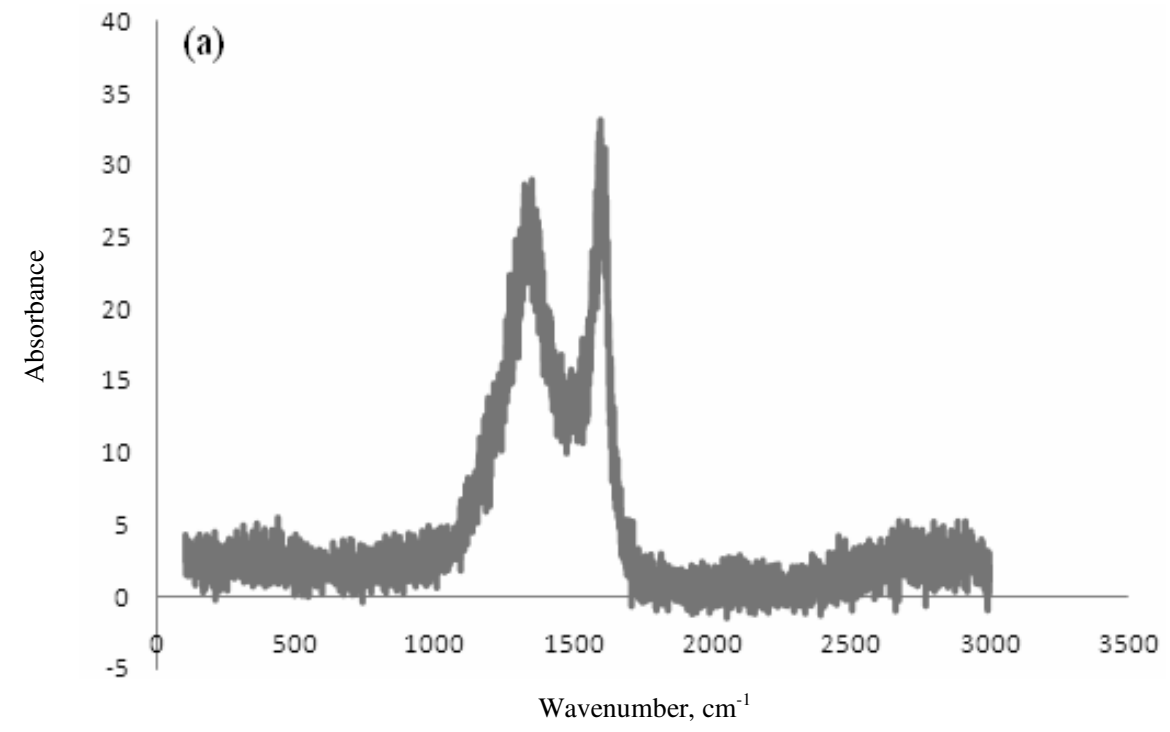




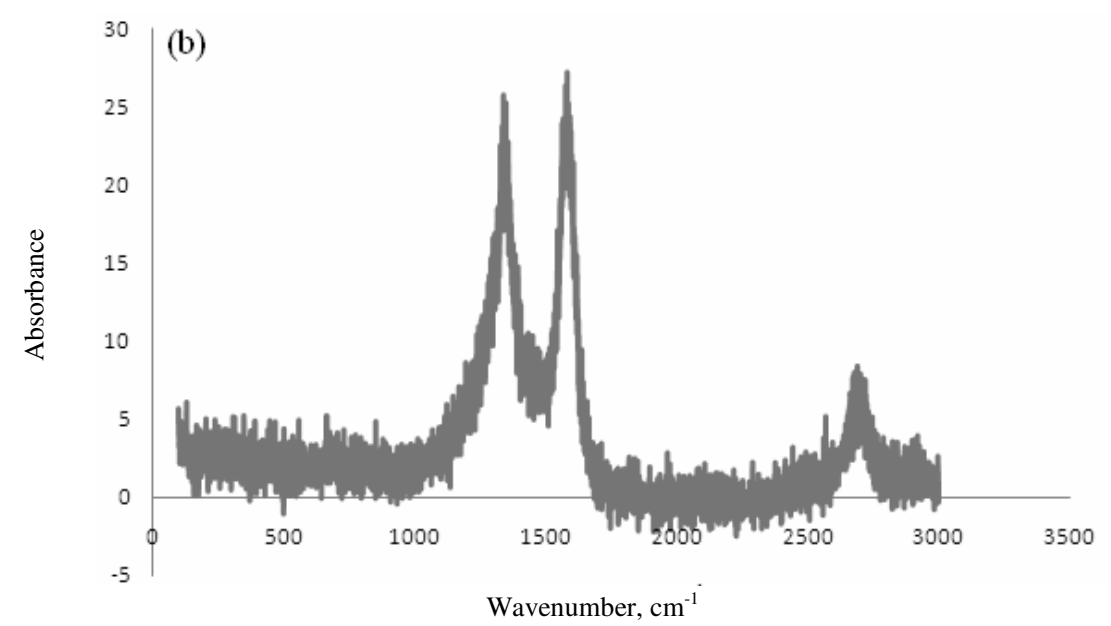

Figure 1. Raman spectra of carbon nanotube grown over (a) $\mathrm{Co} / \mathrm{Zn} / \mathrm{Al}$ and (b) $\mathrm{Fe} / \mathrm{Ni} / \mathrm{Al}$ catalyst

The FE-SEM image of the prepared carbon nanotubes from the catalysts $\mathrm{Co} / \mathrm{Zn} / \mathrm{Al}$ and $\mathrm{Fe} / \mathrm{Ni} / \mathrm{Al}$ are presented in Figure 2. Carbon nanotubes produced from the catalyst $\mathrm{Co} / \mathrm{Zn} / \mathrm{Al}$, Figure 2(a) show clusters of carbon nanotubes encapsulated with a considerable amount of amorphous carbon embedded catalyst particles. Carbon nanotubes produced from the catalyst Fe/Ni/Al, Figure 2(b) shows several cylindrical carbon nanotubes of various lengths. The prepared samples are in association with smaller amounts of other graphitic materials which may be metal catalyst particles. Carbon nanotubes prepared from the catalyst $\mathrm{Fe} / \mathrm{Ni} / \mathrm{Al}$ seems to be better structured than those produced from the catalyst $\mathrm{Co} / \mathrm{Zn} / \mathrm{Al}$.
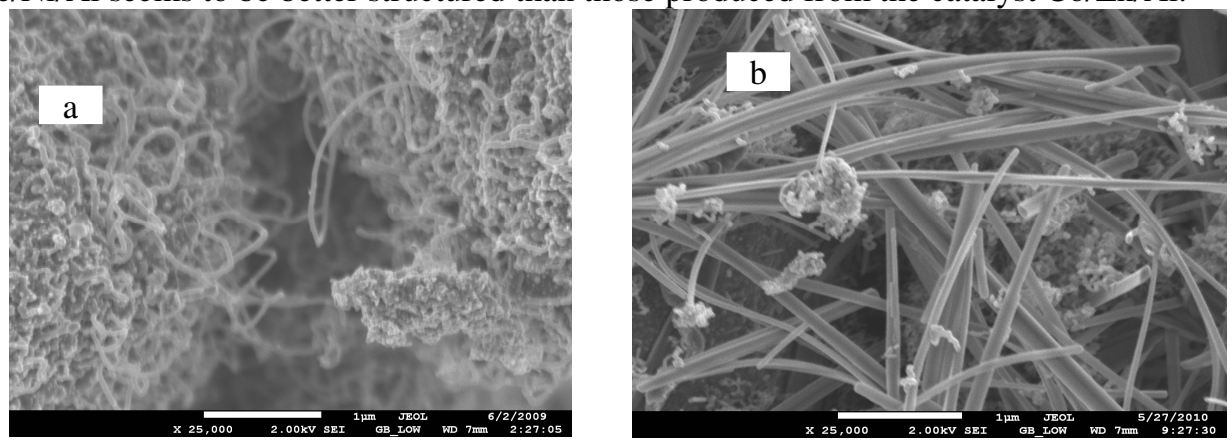

Figure 2. FE-SEM image of carbon nanotubes prepared from (a) $\mathrm{Co} / \mathrm{Zn} / \mathrm{Al}$ and (b) Fe/Ni/Al catalysts

Energy dispersive spectroscopy (EDS), Figure 3, was employed to identify the concentration of catalyst embedded in the carbon nanotubes. The EDS spectra Figure 3(a) shows high concentration of zinc $(\mathrm{Zn})$ and aluminium $(\mathrm{Al})$ metals with respect to cobalt in the prepared CNT. This is an indication of high catalytic activity on the part of cobalt and low catalytic activity on the part of zinc and aluminium, hence, the high intensity on the part of zinc and aluminium with respect to cobalt. In Figure 3(b), the EDS spectra shows a high concentration of aluminium with respect to iron $(\mathrm{Fe})$ and nickel $(\mathrm{Ni})$, indicating that iron and nickel metals were involved in the catalytic activity of converting ethyne to carbon nanotubes. 

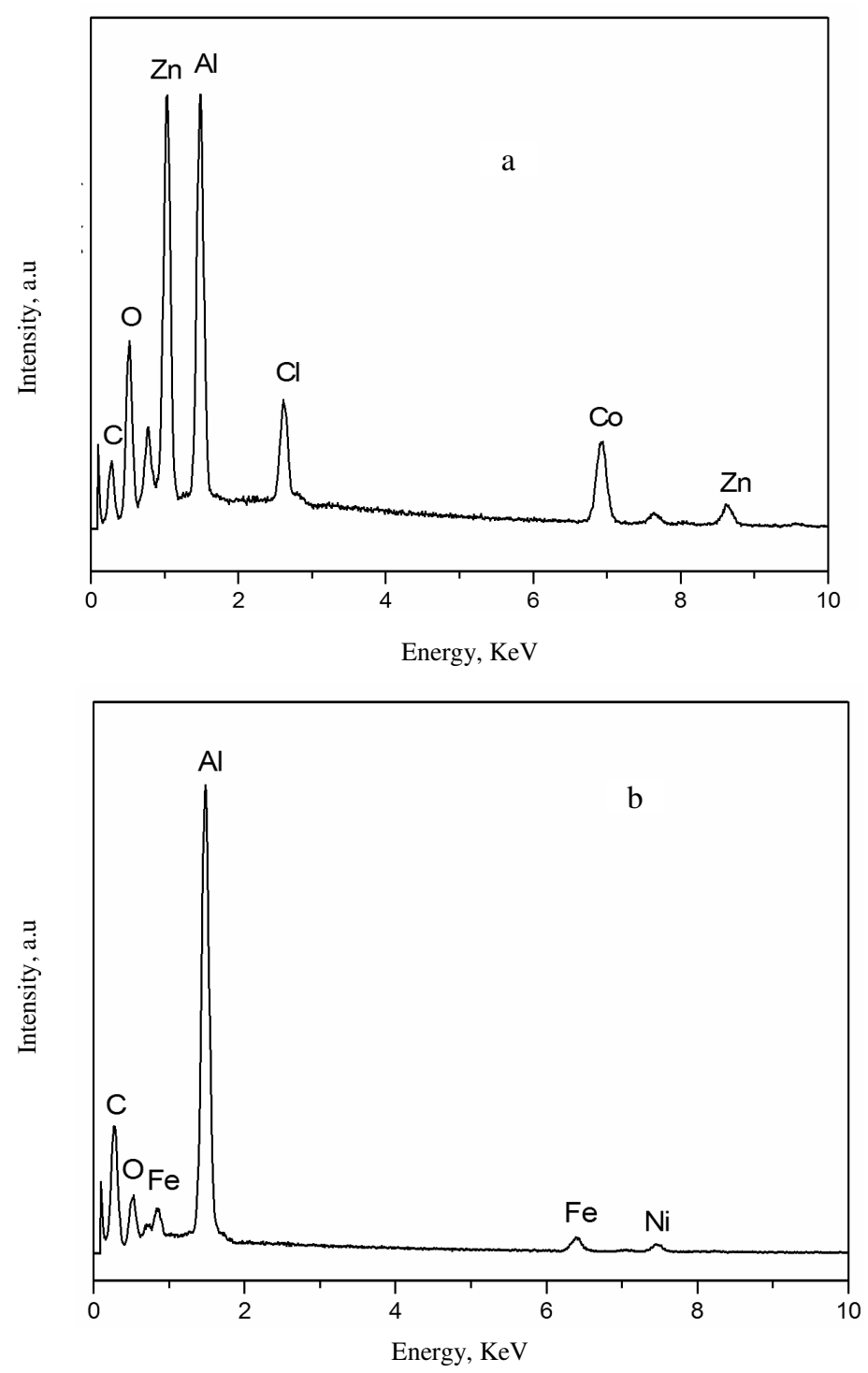

Figure 3. EDS spectra of carbon nanotube prepared from (a) $\mathrm{Co} / \mathrm{Zn} / \mathrm{Al}$ and (b) $\mathrm{Fe} / \mathrm{Ni} / \mathrm{Al}$ catalysts.

The HR-TEM micrograph of the prepared CNTs from the catalysts $\mathrm{Co} / \mathrm{Zn} / \mathrm{Al}$ and $\mathrm{Fe} / \mathrm{Ni} / \mathrm{Al}$, by decomposition of ethyne (acetylene) are presented in Figure 4. The TEM image at $20 \mathrm{~nm}$ magnification, Figure 4(a and b), of the prepared carbon nanotubes obtained from the catalyst $\mathrm{Co} / \mathrm{Zn} / \mathrm{Al}$ shows several particles of solid catalyst along a strand of a nano carbon fiber. The figure also show a cluster of amorphous carbon with black dots which are thought to be metallic nanoparticles of catalysts with a single carbon nanotubes at $50 \mathrm{~nm}$. The HR-TEM micrograph of the prepared CNTs from the catalyst Fe/Ni/Al, Figure 4(b and c), at 200 and $20 \mathrm{~nm}$ magnifications is a typical high resolution TEM image of carbon nanotubes. The images at these magnifications indicate that there are catalyst particles encapsulated with the grown CNT which show that the CNT grew from the catalyst particles. 
In Figure 4(e), at $5 \mathrm{~nm}$ magnification; we see the tube consisting of several graphitic layers, approximately 60 layers with a hollow in the middle. There are literature reports that the use of iron and nickel as catalysts leads to the formation of carbon nanotubes with an outer layer of thick amorphous carbon ${ }^{24,25}$. The outer layer of the carbon nanotubes in this figure shows a thick layer of amorphous carbon. The TEM image indicates that the carbon nanotubes are multiwalled. From these HR-TEM images, we observe that carbon nanotubes prepared from $\mathrm{Fe} / \mathrm{Ni} / \mathrm{Al}$ contained multiwalled carbon nanotubes which were not observed in the CNTs from the catalyst $\mathrm{Co} / \mathrm{Zn} / \mathrm{Al}$.
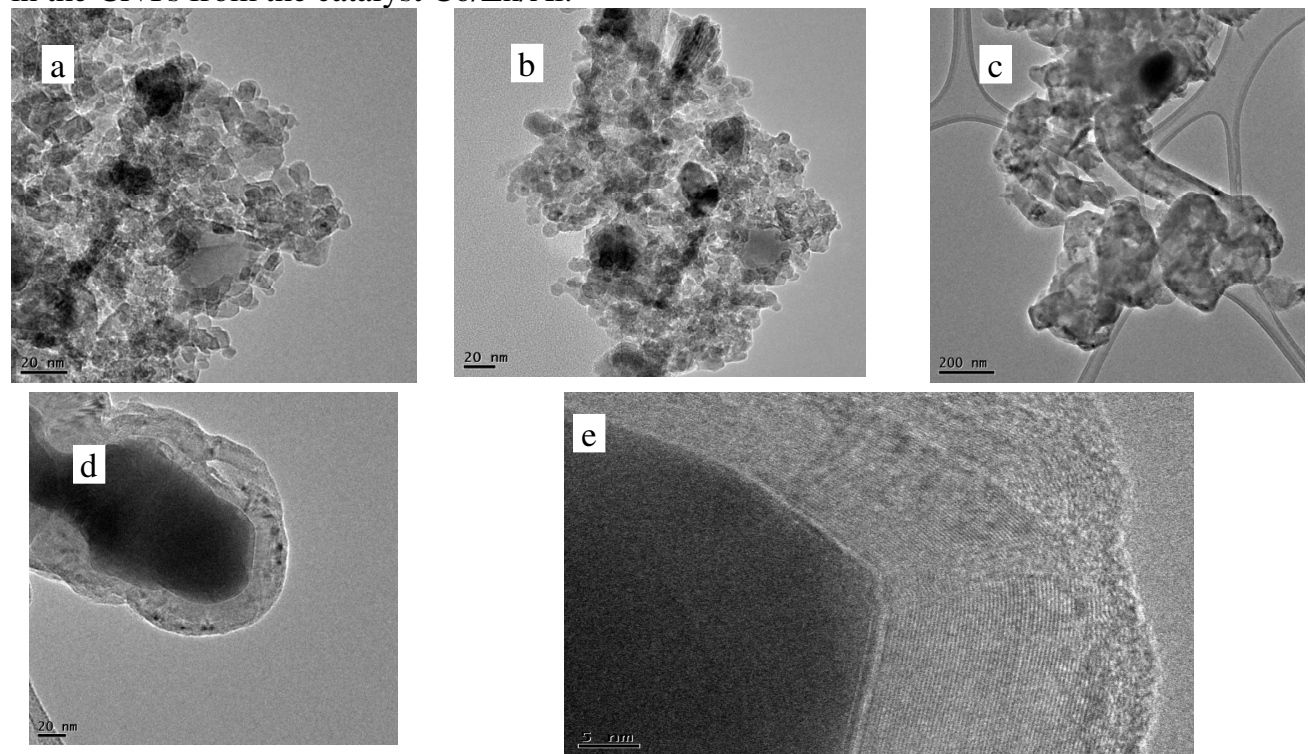

Figure 4. TEM image of carbon nanotube prepared from $\mathrm{Co} / \mathrm{Zn} / \mathrm{Al}$ (a and b) and $\mathrm{Fe} / \mathrm{Ni} / \mathrm{Al}$ (c, d and e) catalysts. Figure 4(e) is a higher magnification of Figure 4(d).

The TGA profile of the CNTs is presented in Figure 5. TGA analysis was employed to examine the thermal stability of the prepared CNTs over $\mathrm{Co} / \mathrm{Zn} / \mathrm{Al}$ and $\mathrm{Fe} / \mathrm{Ni} / \mathrm{Al}$ catalyst. Thermogravimetric (TGA) and the derivative thermogravimetric (DTG) curve of the weight loss are in most instances used to investigate the presence of carbon nanotubes. The interpretations of these curves are not straight forward due to the presence of catalyst particles during weight loss analysis. The temperature at which the CNTs are oxidized is an index of its stability. The TGA graph show the TGA and derivative thermogravimetric curve of the prepared CNTs. Thermogravimetric analysis of a sample of carbon nanotubes obtained from the catalyst system $\mathrm{Co} / \mathrm{Zn} / \mathrm{Al}$ is presented in Figure 5(a). Weight loss started at $370{ }^{\circ} \mathrm{C}$ to about $880{ }^{\circ} \mathrm{C}$. There are apparently several combustion regions observable from the TGA graph which may be credited to the decomposition of carbonaceous materials along with the CNTs and the catalyst. The derivative thermogravimetric curve (DTA), shows several peaks which suggest that there are carbon components within the sample which is in agreement with TEM measurement. The DTA profile show both exothermic and endothermic processes occurring simultaneously resulting in thermolysis of the solid. Exothermic peaks at $420,570,600$ and $620{ }^{\circ} \mathrm{C}$ could be ascribed as oxidation processes in the solid sample while a single endothermic process could be observed at about $550{ }^{\circ} \mathrm{C}$. The TGA profile of the CNTs obtained from the catalyst system $\mathrm{Fe} / \mathrm{Ni} / \mathrm{Al}$ is presented in Figure 5(b). Weight loss started at $582{ }^{\circ} \mathrm{C}$ to about $670{ }^{\circ} \mathrm{C}$ for the sample. It is interesting to note from the weight loss 
analysis that only $30 \%$ of the carbonaceous material was burnt. No other secondary combustion took place during the TGA analysis. The curve of the derivative weight loss analysis shows only a single sharp peak with a broad base at $632{ }^{\circ} \mathrm{C}$. The thermogravimetric analysis of the carbon nanotubes produced from both catalysts systems show the carbon nanotubes produced from the $\mathrm{Fe} / \mathrm{Ni} / \mathrm{Al}$ catalyst system to contain less carbonaceous material, as such, showed a single exothermic oxidation process.
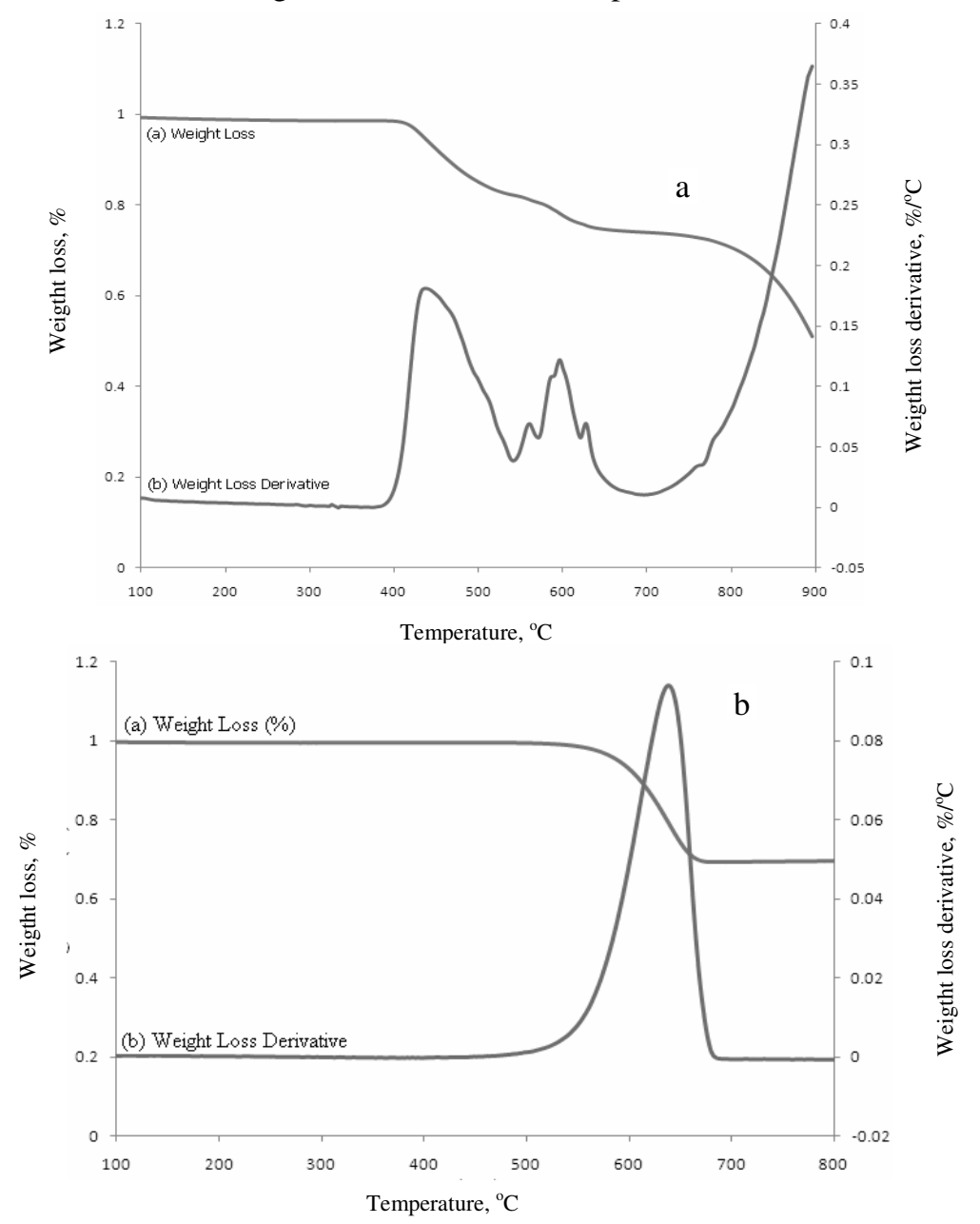

Figure 5. TGA and derivative thermogravimetric plot profile of MWCNT obtained from (a) $\mathrm{Co} / \mathrm{Zn} / \mathrm{Al}$ and (b) $\mathrm{Fe} / \mathrm{Ni} / \mathrm{Al}$ catalysts.

\section{Conclusion}

Carbon nanotubes have been grown from the catalytic decomposition of ethyne in a CCVD chamber with the catalyst $\mathrm{Fe} / \mathrm{Ni} / \mathrm{Al}$ and $\mathrm{Co} / \mathrm{Zn} / \mathrm{Al}$. The morphology of carbon nanotubes produced depends on the nature of the catalyst used in the synthesis. The catalyst system $\mathrm{Fe} / \mathrm{Ni} / \mathrm{Al}$ produced higher quality carbon nanotubes with regular cylindrical shapes compared to the catalyst system $\mathrm{Co} / \mathrm{Zn} / \mathrm{Al}$, which produced comparatively lower quality carbon nanotubes. 
The TGA of the carbon nanotubes synthesized from catalyst $\mathrm{Fe} / \mathrm{Ni} / \mathrm{Al}$, produced a single exothermic oxidation peak while the carbon nanotubes synthesized from the catalyst $\mathrm{Co} / \mathrm{Zn} / \mathrm{Al}$, produced several peaks during thermogravimetric analysis. Raman spectra of carbon nanotubes produced from the catalyst $\mathrm{Fe} / \mathrm{Ni} / \mathrm{Al}$, produced a very important overtone which was not found in the spectra of the carbon nanotubes synthesized from the catalyst $\mathrm{Co} / \mathrm{Zn} / \mathrm{Al}$.

\section{Acknowledgment}

This work was supported by a research grant from the Faculty of Applied and Computer Science Research and Publications Committee of Vaal University of Technology, Vanderbijlpark.

\section{Reference}

1. Harries P J F, Carbon Nanotubes Science: Synthesis, Properties and Applications. Cambridge University Press: Cambridge, 2009.

2. Iijima S, Nature, 1991, 354(7), 56-58.

3. Yang H, Mercier P, Wang S C and Akins D L, J Chem Phys Lett., 2005, 416, 18 - 21.

4. Benito P, Herrero M, Labajos F M, Rives V, Royo C, Latorre N and Monzon A, Chem Eng J., 2009, 149, 455 - 462

5. Dreeelhaus M S, Dresselhaus G and Avouris P H. (Eds), Carbon nanotubes: Synthesis, Structure, Properties and Applications, Springer-Verlag: Berlin, 2001.

6. Dresselhaus M S, Lin Y M, Rabin O, Jorio A, Souza-Filho A G, Pimenta M A, Saito R Samsonidze R, Ge G and Dresselhaus G, Mater Sci Eng C., 2003, 23, 129 - 140.

7. Han J T, Woo J H, Kim H S and Jee J G, Bull Korean Chem Soc., 2003, 24(12), 1771- 1774

8. Guo T, Nikolaev P, Rinzler A G, Tomanek D, Colbert D T and Smalley R E, $J$ Phys Chem., 1995, 99, 10694-10697

9. Yudasak M, Komatsu T, Ichihashi T and Iijima S, J Chem Phys Lett., 1997, 278, 102-112

10. Ren Z F, Huang Z P, Xu J W, Wang J H, Bush P S, Siegel M P, Provencio P N and Provencio, P N, Sci., 1998, 282(6), 1105-1107.

11. Ivanov V, Fonseca A, Nagy J B, Lucas A, Lambin P, Bernaerts D, et al. Carbon 1995, 33, 1727 - 1738.

12. Hsieh C T, Lin Y T, Lin J Y and Wei J L, Mater Chem Phys., 2009, 114, 702-708

13. Zhang T and Amiridis M D, J Appl Catal A., 1998, 167, 161

14. Kuvshinov G G, Mogilnykh Y I, Kuvshinov D G, Zaikvskii V I and Avdeeva L B, Carbon, 1998, 36, 87.

15. Sinnott S B, Andrews R, Qian D, Rao A M, Mao Z, Dickey E C and Derbyshire F, $J$ Chem Phys Lett., 1999, 315, 25-30

16. Aiello R, Fiscus J E, Loye H C and Amiridis M D,. J Appl Catal A., 2000, 192, 227-232

17. Rives V, Layered Double Hydroxides: Present and Future, Ed., Nova Science Publishers: New York, 2001.

18. Liu J, Shao M, Chen X, Yu W, Liu X and Qian Y, J Am Chem Soc., 2003, 125(27), 8088.

19. Srivastava S K, Vankar V D and Kumar V, J Thin Solid Films, 2006 515, 1552 -1560.

20. Eftekhari A, Jafarkhani P and Moztarzadeh F, Carbon, 2006 44, 1343 -1345.

21. Morales M R, Barbero B P and Cadus L E, J Appl Catal B., 2007, 74, 1 -10.

22. Zeifert B H, Salmones J, Hernandez J A, Reynoso R, Nava N and Cabanas-Moreno J G, Aguilar-Rios G, Mater Lett., 2000, 43, 244 - 248.

23. Dikio E D, Thema F T, Dikio C W and Mtunzi F M, Int J Nanotech Appl., 2010, 4, 117-124.

24. Kibria F A K M, Mo Y H, Nahm K S and Kim M J, Carbon, 2002, 40, 1241 - 1247.

25. Zhang Q, Zhao M, Huang J, Qian W and Wei F, Chin J Catal., 2008, 29, (11) 1138 - 1144. 


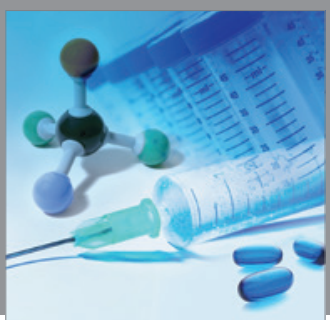

International Journal of

Medicinal Chemistry

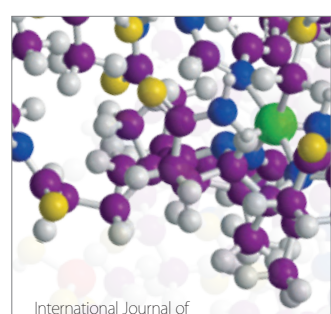

Carbohydrate Chemistry

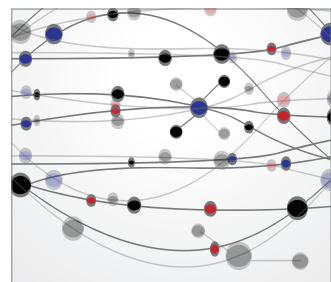

The Scientific World Journal
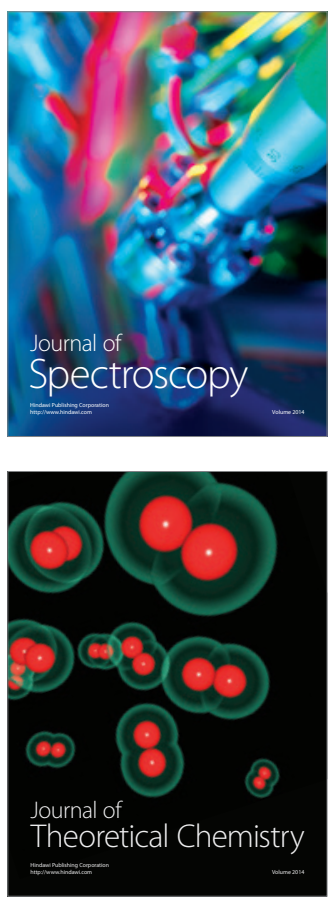
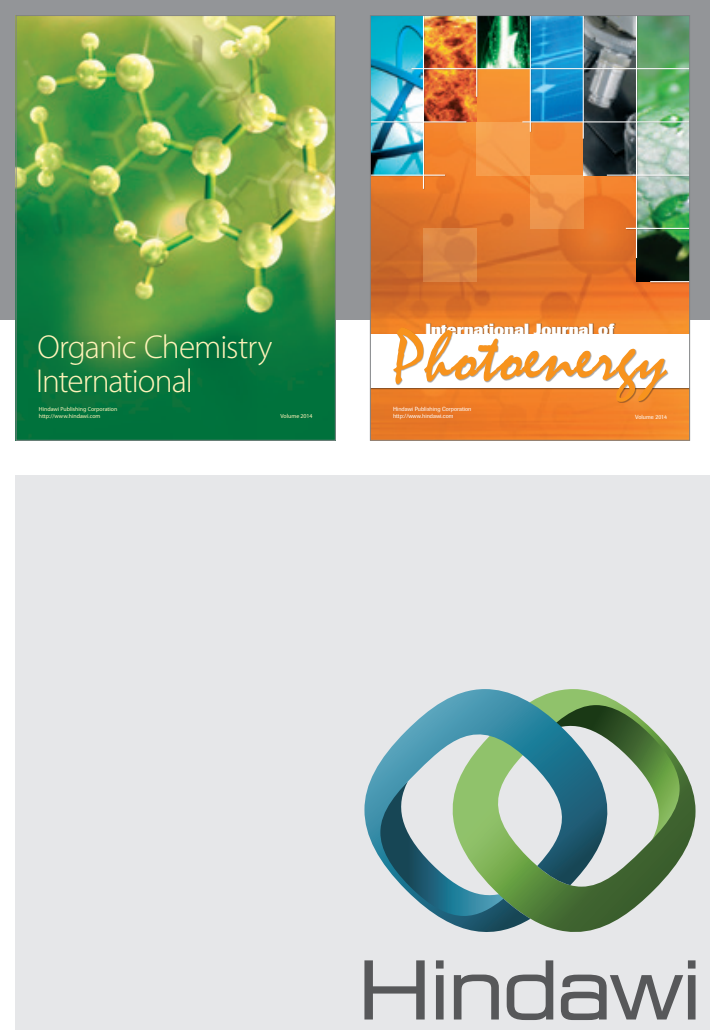

Submit your manuscripts at

http://www.hindawi.com
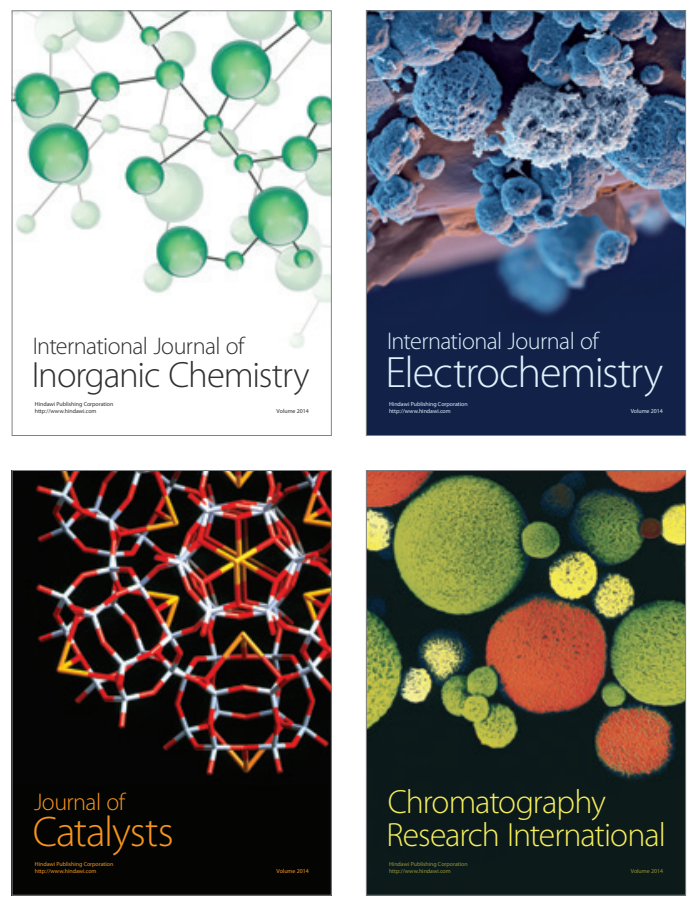
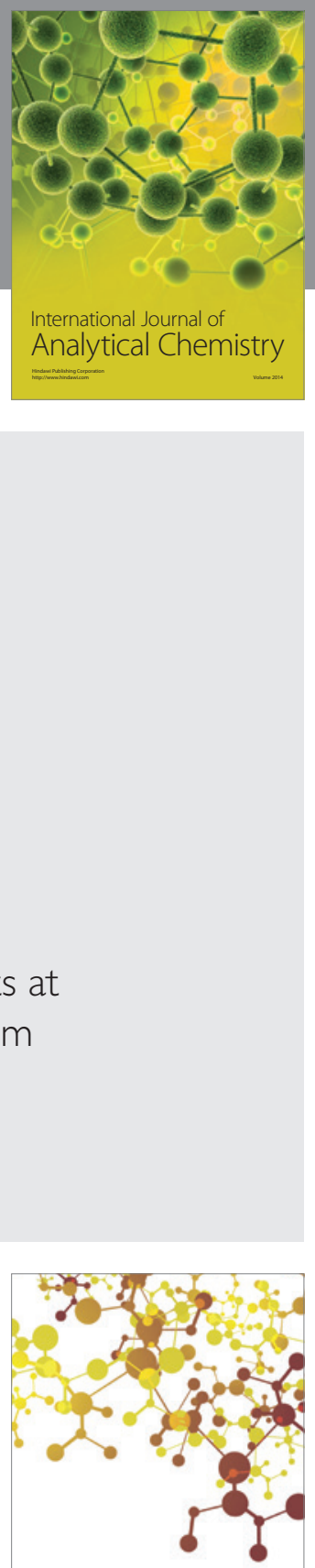

Journal of

Applied Chemistry
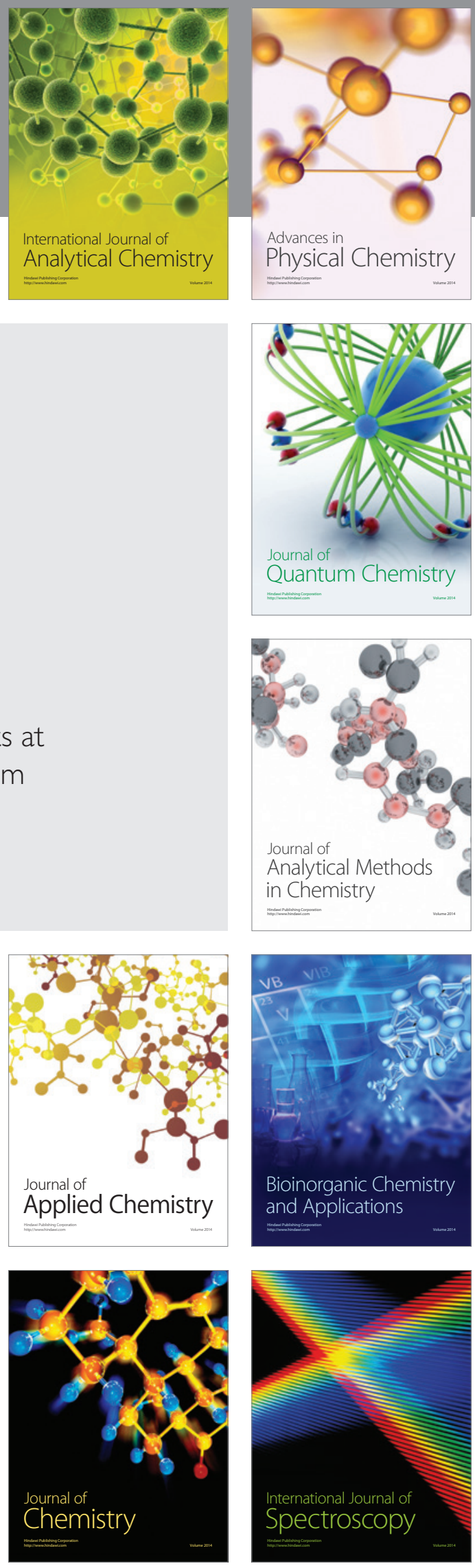